\title{
TREMATODES DETECTION AND TREATMENT ON NILE TILAPIA FROM ELIBRAHIMIYAH CANAL IN ASSUIT CITY, EGYPT
}

\author{
Wafaa G. Mahmoud ${ }^{1}$, Nagwa T. Elsharawy ${ }^{2}$ and Mahmoud Hashem ${ }^{3}$ \\ 1- Parasitology Department, 2- Food Hygiene Department, 3- Fish Disease Department, Faculty of Vet. Med., New \\ Valley, Assuit University, Egypt
}

This study was designed to determine the fish parasites metacercariae on Elibrahimiyah Canal (from River Nile) in Assuit governorate and test the effect of freezing on the viability of parasite on Nile Tilapia "Oreochromisniloticus". Six hundred and twenty of Nile Tilapia fish were caught from Elibrahimiyah Canal, samples were measured, weighed, and then efficiently inspected of the skin, gills, internal organs, and musculature grossly and microscopically with and without stain. Positive parasitism's fish stored under freezing condition below $-4^{\circ} \mathrm{C}$ to $-7^{\circ} \mathrm{C}$ for about 7 days to test the effect of freezing on its viability. The results referred that, the total prevalence rate of Clinostomum spp. And Euclinostomumardeolae metcercaria infection in Nile Tilapia were about $(6.45 \%)$ totally as following; (1.61\%) and $(4.84 \%)$ for Clinostomum spp. and Euclinostomumardeolae metcercaria infection respectively. Macroscopic and Microscopic Examination of Euclinostomumardeolae metacercaria and Clinostomum spp. declared their shape in details. In addition to the inhibition effect of freezing on the Viability of Euclinostomumardeolae and Clinostomum spp. metacercaria. In conclusion, the evident of the parasites in Nile tilapia belonging to Elibrahimia Canal are rarely. Freezing of fish meat before consumption has effective effect to kill viable metacercaria.

Keywords: Snails, Euclinostomumardeolae, Clinostomum spp., metacercaria, zoonosis, freezing 